\title{
Refined mapping of the human serotonin transporter (SLC6A4) gene within 17q11 adjacent to the CPD and NF1 genes
}

\author{
Sanbing Shen ${ }^{1}$, Sharon Battersby ${ }^{1}$, Molly Weaver ${ }^{2}$, Elma Clark ${ }^{1}$, Karen Stephens ${ }^{2,3}$ and \\ Anthony J Harmar ${ }^{1}$ \\ ${ }^{1}$ MRC Brain Metabolism Unit, University Department of Neuroscience, Edinburgh, Scotland; Departments of \\ ${ }^{2}$ Medicine and ${ }^{3}$ Laboratory Medicine, University of Washington, Seattle, WA 98195, USA
}

The SLC6A4 gene encodes the serotonin transporter, the target of an important class of antidepressant drugs (serotonin selective reuptake inhibitors). Polymorphisms in the SLC6A4 gene have been reported to be associated with susceptibility to depression and other psychiatric disorders. We have constructed a $1 \mathrm{Mb}$ YAC and PAC contig which harbours both the SLC6A4 and the carboxypeptidase D (CPD) genes. The order of loci within the contig was cen-D17S975-D17S1549-24R-D17S1294-SLC6A4-28L-(CPD, D17S2009, D17S2004)-D17S2120-ter. Both genes were deleted in one of 17 neurofibromatosis type 1 (NF1) patients carrying submicroscopic NF1 contiguous gene deletions. European Journal of Human Genetics (2000) 8, 75-78.

Keywords: serotonin transporter; CPD; NF1; YAC contig

\section{Introduction}

The actions of the neurotransmitter serotonin (5-HT) are terminated by reuptake via a $\mathrm{Na}^{+}$-dependent serotonin transporter (SERT) encoded by the SLC6A4 gene. The SERT is the target for an important class of antidepressant drugs (the serotonin selective reuptake inhibitors) and also of certain drugs of abuse including 3,4-M ethylenedioxymethamphetamine (MDMA or 'ecstasy'). Polymorphisms in the SLC6A4 gene have been reported to be associated with depression and other psychiatric disorders and to influence personal ity traits (reviewed by Lesch ${ }^{1}$ ). To facilitate studies of the molecular basis of these associations, we have constructed a map of a $1 \mathrm{Mb}$ region encompassing the human SLC6A4 and CPD genes. We have evaluated the contribution of these genes to the phenotype observed in patients with NF1 contiguous gene deletions.

\section{Materials and methods}

Construction and analyses of physical contig Positive clones were identified by hybridisation of $\left[\alpha{ }^{32} \mathrm{P}\right] \mathrm{dCTP}-\mathrm{labelled}$ SLC6A4 CDNA to the RPC-1 PAC library

Correspondence: Dr Sanbing Shen, MRC Brain Metabolism Unit, University Department of Neuroscience, 1 George Square, Edinburgh, EH8 9JZ, Scotland, UK. Tel: +44 1315376527; Fax: +44 1315376110; E-mail: Sanbing.Shen@ed.ac.uk

Received 19 April 1999; revised 5 July 1999; accepted 6 August 1999 and YAC libraries from ICRF (35D8, 132C6 and 49A9) and CEPH (704F1, 782E2 and 765D1). Yeast DNA was prepared by combined methods of Schedl et $\mathrm{al}^{2}$ and Bellis et al. ${ }^{3}$ Pulsedfield gel electrophoresis was performed in $0.5 \times$ TBE buffer at $6 \mathrm{~V} / \mathrm{cm}$ for $24 \mathrm{~h}$ at $14^{\circ} \mathrm{C}$ with $60 \mathrm{~s}$ switch time and gels were blotted overnight onto Appligene Positive Membrane. Filters were sequentially hybridized with: (i) a 854 bp Pst I fragment of SLC6A4 cDNA (bp 785-1639, GenBank accession no. L05568); (ii) a $2.3 \mathrm{~kb}$ Eco RI-Pvu II fragment of pBR322; (iii) 28L, a $3.2 \mathrm{~kb}$ Not I - Eco RI fragment of PAC 50G6, about $40 \mathrm{~kb} 5^{\prime}$ of the SLC6A4 gene adjacent to the T7 promoter sequence from the vector PCYPAC2N; (iv) $24 \mathrm{R}$, a $8.4 \mathrm{~kb}$ Not I - Hind III fragment of PAC 50G6, about $15 \mathrm{~kb} 3^{\prime}$ of the SLC6A4 coding sequence adjacent to the SP6 promoter sequence of the vector. YACs were sized by hybridisation to pBR322 plasmid DNA, using the endogenous yeast chromosomes as size references. PCR was performed for 30 or 35 cycles with primers listed in Table 1.

\section{Patient and somatic cell hybrid lines}

Patient UWA106-3 is hemizygous for a microdeletion of about $1-1.5 \mathrm{Mb}$ that spans the entire NF1 gene. ${ }^{4}$ The human/ rodent somatic hybrid cell lines UWA106-3-\#36 and UWA106-3-\#41 harbour, respectively, the deleted and nondeleted chromosomes 17 from this patient. ${ }^{4}$ Fluorescence in 
situ hybridisation (FISH) was carried out with biotin11-dATP-labelled 50G6 PAC DNA. ${ }^{5}$

\section{Results}

\section{Characterisation of the SLC6A4 gene and PAC clones}

Long-range PCR of human genomic DNA with six pairs of primers indicated that the SLC6A4 gene spanned approximately $40 \mathrm{~kb}$ (Table1). One PAC (50G6) contained the entire coding sequence of the SLC6A4 gene. Southern blot analysis of Notl digested $50 \mathrm{G} 6$ DNA revealed a $40 \mathrm{~kb}$ fragment that hybridised to end clone $28 \mathrm{~L}$, a $55 \mathrm{~kb}$ fragment that hybridised to end clone $24 \mathrm{R}$, and a $16 \mathrm{~kb}$ fragment from the PAC vector (data not shown). We concluded that 50G6 contains the entire SLC6A4 geneflanked by about $40 \mathrm{~kb}$ of 5 ' sequence and about $15 \mathrm{~kb}$ of $3^{\prime}$ sequence.

\section{Construction of SLC6A4 contig}

The contig depicted in Figure 1 was assembled by analysis of 6 YACs and the PAC $50 \mathrm{G} 6$ for the presence of 6 STS markers and for the PAC end clones $24 \mathrm{R}$ and $28 \mathrm{~L}$. Five of the six YACs harboured the entire SLC6A4 gene, whereas 704F1 lacked the 5 ' untranslated region and first exon. These data oriented the $3^{\prime}$ end of the SLC6A4 gene towards the chromosome 17 centromere. D17S1294 mapped $<15 \mathrm{~kb}$ centromeric to the $3^{\prime}$ end of the SLC6A4 gene, since it was present in 704F1 but not in 49A9. All clones carried the 10 repeat allele of SLC6A4 intron 2 polymorphism; ${ }^{6}$ YAC clones from ICRF library carried the short allele of the promoter polymorphism, ${ }^{7}$ while those from the CEPH library carried the long allele.

\section{Carboxypeptidase D gene maps telomeric to SLC6A4}

A $163 \mathrm{~kb}$ genomic sequence from human chromosome17 (GenBank AC006050) encodes the entire CPD gene, with D17S2004 and D17S2009 within the predicted 3' untranslated region. The presence of the CPD gene in YACs 35D8, 765D1 and 49A9 was confirmed using both forward primers of D17S2009 and D17S2004 and with two pairs of primers (cpd6740F/cpd6858R, and cpd1065F/cpd1768R: Table1) from CPD CDNA. We concluded that the CPD gene lies telomeric to the SLC6A4 gene within the contig.

\section{Hemizygotic deletion of the SLC6A4 and CPD genes in a NF1 patient}

Our YAC contig does not contain the NF1 gene, since none of the YAC clones yielded products with PCR primer pairs from exons 1, 27a and 49.2 of the gene. ${ }^{8}$ However, because the deletion in UWA106-3 included loci predicted to map nearer the centromere than SLC6A4, we subjected metaphase chromosomes prepared from immortalised lymphoblasts of this patient to FISH using 50G6 as the probe. Only one hybridisation signal was observed, confirming the hemizygosity of the SLC6A4 locus (Figure2a). PCR of DNA from rodent/human somatic hybrid cell lines carrying either the deleted or non-deleted chromosomes 17 of UWA106-3 indicated that the deletion encompassed the CPD and SLC6A4 genes and D17S2120 but not D17S1294 or D17S1549 (Figure $2 b$ ). Therefore, the centromeric breakpoint of the deletion in this patient lies in a $<15 \mathrm{~kb}$ region between exon 14 of the SLC6A4 gene and D17S1294 (arrow head, Figure1b). Neither the SLC6A4 nor the CPD gene was deleted in 16 additional NF1 microdeletion patients ${ }^{4}$ examined.

\section{Discussion}

We report here the construction of a $1 \mathrm{Mb}$ contig encompassing the SLC6A4 and CPD genes and eight marker loci. Our results confirm the localisation of $\mathrm{SLC} 6 A 4^{9,10}$ and $C P D^{11}$ to chromosome17q11.2-17q12. The SLC6A4 and CPD genes were deleted in 1/17 NF1 microdeletion patients tested, but our data suggest that the majority of such patients will not be haploinsufficient for SERT and CPD. The identification of eight marker loci flanking the SLC6A4 and CPD genes will facilitate future studies of their role in susceptibility to developmental and psychiatric disorders. This contig will also provide a centromeric anchor for chromosomal walking towards the NF1 gene, which may lead to the discovery of other genes contiguous to NF1. Functional analysis of these

Table 1 PCR primers for SLC6A4 and CPD genes

\begin{tabular}{|c|c|c|c|c|c|}
\hline \multicolumn{2}{|c|}{ Forward primers $\left(5^{\prime}-3^{\prime}\right)$} & \multicolumn{2}{|c|}{ Reverse primers $\left(5^{\prime}-3^{\prime}\right)$} & \multirow{2}{*}{$\begin{array}{l}\text { Product } \\
\text { SLC6A4 5-HTTLPR }\end{array}$} & \multirow{2}{*}{$\begin{array}{l}\text { Size } \\
458 / 502 b p\end{array}$} \\
\hline 31013 & CACCTAACCCCTAATGTCCCTACT & 31014 & GGACTGAGCTGGACAACCAC & & \\
\hline $1 \mathrm{AP}(\mathrm{F})$ & GCGTCTAGGTGGCACCAGAATC & $1 \mathrm{AP}(\mathrm{R})$ & TCGCGCTTGTGTTCCCAGCTAC & SLC6A4 Exon 1a & $545 \mathrm{bp}$ \\
\hline 43084 & CCTGCGAGGAGGCGAGGAGG & 43085 & AACTCCTCTCGGTGACTAATCG & SLC6A4 Exon 1-Intron 1a & $10 \mathrm{~kb}$ \\
\hline 44771 & CTAGTGACTGACATTGCCTGG & 44772 & TGTCCAGTCTATCTGCACATG & SLC6A4 Exon 1b & 824 bp \\
\hline 43088 & GCCTGGCGTTGCCGCTCTGAATGC & 43089 & TAGCAGCAGCAGTGAGCAGTTACC & SLC6A4 Intron 1a-Exon 2 & $3.5 \mathrm{~kb}$ \\
\hline 26373 & ACTAACCAGCAGGATGGAGACG & 26374 & TAGAGTGCCGTGTGTCATCTCC & SLC6A4 Exon 2 & $199 \mathrm{bp}$ \\
\hline 18564 & GTCAGTATCACAGGCTGCGAG & 18565 & TGTTCCTAGTCTTACGCCAGTG & SLC6A4 Intron 2 VNTR & $249 / 266 / 299$ bp \\
\hline $\mathrm{E} 2 \mathrm{~F}$ & ACTAACCAGCAGGATGGAGACG & $2 \mathrm{~B}$ & TTAGACCGGTGGATCTGCAG & SLC6A4 Exons 2-5 & $5 \mathrm{~kb}$ \\
\hline 54073 & TGGCAAGGTGAGGAAGGCTCTGG & 54074 & CCACCTCAGACACATCTTCATTCC & SLC6A4 Exons 5-8 & $4 \mathrm{~kb}$ \\
\hline $5 \mathrm{~A}$ & ATGAAGATGTGTCTGAGGTGG & $5 B$ & ACAGCGACTGCTTCGATCAG & SLC6A4 Exons 8-11 & $3.8 \mathrm{~kb}$ \\
\hline $6 \mathrm{~A}$ & TACGTGGTGAAGCTGCTGGA & P3 & GAGGAGGAGGTTGTGGAGAAGCC & SLC6A4 Exons 11-14 & $>12 \mathrm{~kb}$ \\
\hline 26375 & AGTTCTGATGAGGCACGC & 26376 & TTCATCACCTCCATCCACATCC & SLC6A4 Exon 14 & $223 \mathrm{bp}$ \\
\hline 60703 & ATCACATTAGAACTGTCTTGTTGC & 60704 & AGGTATTCTATGAGGTTCAACAGC & CPD $1065 F+C P D 1768 R$ & $2.7 \mathrm{~kb}$ \\
\hline 60705 & TTATGTAGTTCAGTAAGATGTGCC & 60706 & GCAAGTATTCTTCAACTGGATAGG & CPD $6740 F+C P D 6858 R$ & $118 \mathrm{bp}$ \\
\hline
\end{tabular}




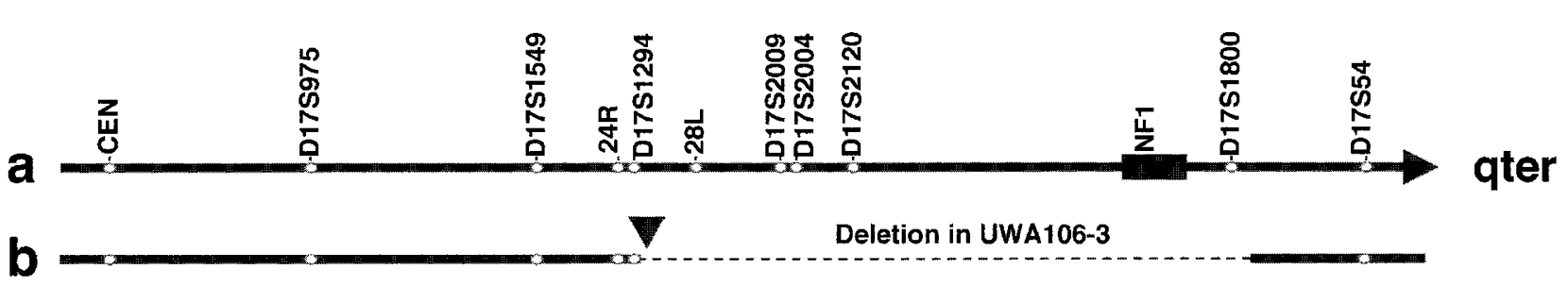

C

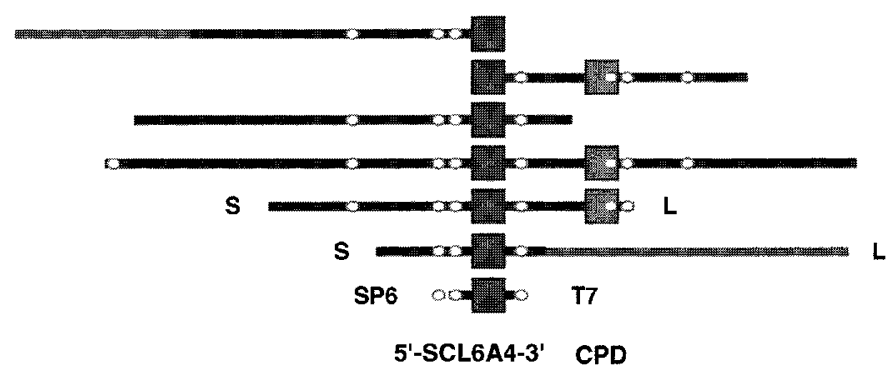

704F1 (640 kb)

$49 \mathrm{~A} 9(230 \mathrm{~kb})$

$782 \mathrm{E} 2(600 \mathrm{~kb})$

765D1 (1000 kb)

$35 \mathrm{D} 8(500 \mathrm{~kb})$

$132 \mathrm{C} 6(630 \mathrm{~kb})$

$50 \mathrm{G} 6(95 \mathrm{~kb})$

Figure 1 Mapping of the SLC6A4 and CPD genes to 17q11 in a YAC/PAC contig. a Physical map of the region between 17cen and D17S54; $\quad$ b the extent of the deletion (- - ) in the patient UWA106-3; c positions of the SLC6A4 ( $\square$ ) and CPD $\mathbb{N}$ genes, STS markers and other probes (circles) in 6YACs and one PAC (50G6) clone. Putative regions of chimaerism in YACs 704F1 and $132 \mathrm{C} 6$ are shaded. The orientations of the long (L) and short (S) YAC vector arms are indicated where known. Orientation of the insert in PAC $50 \mathrm{G} 6$ is shown relative to the SP6 and T7 promoters of the vector.
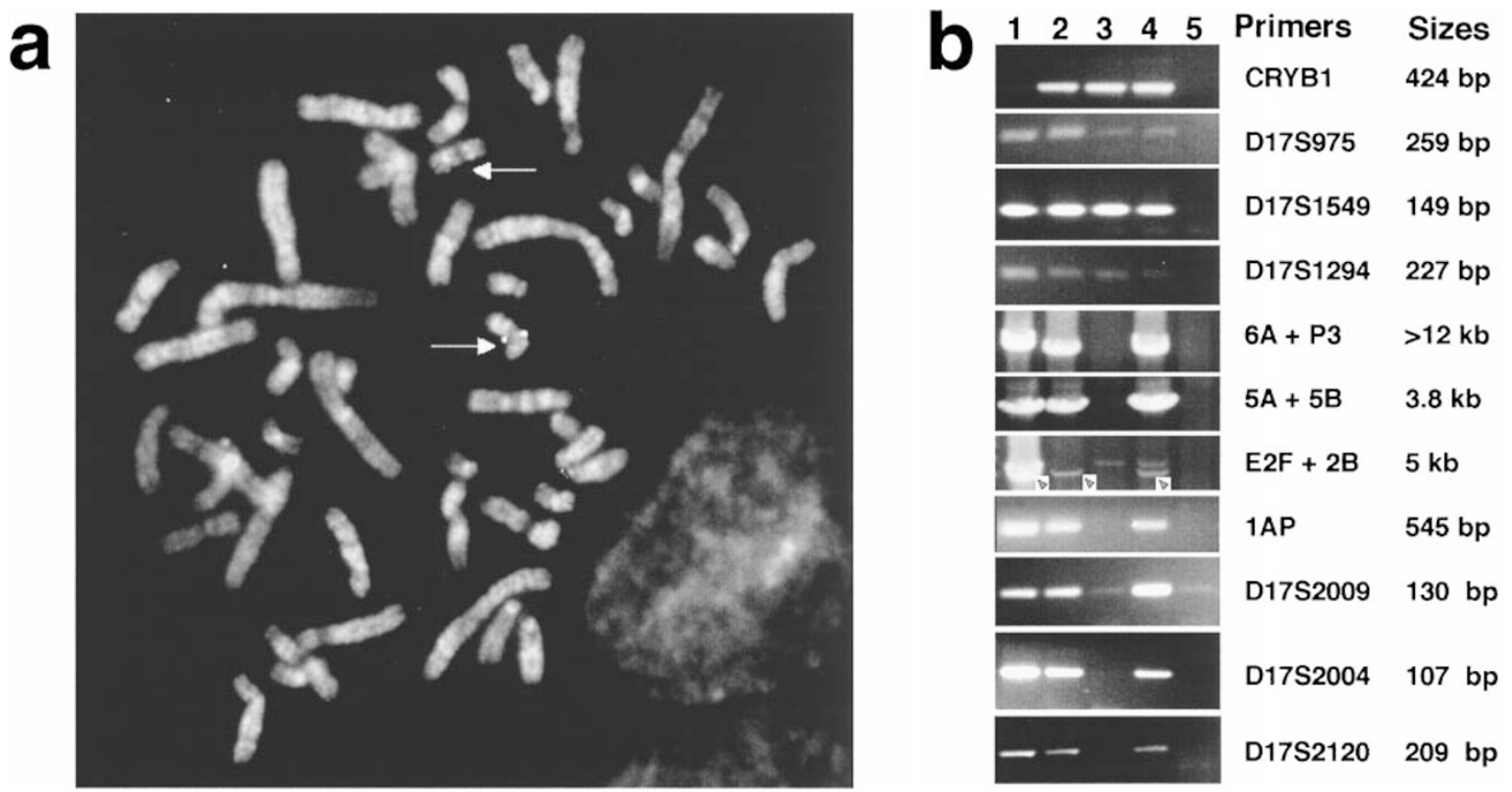

Figure 2 a Hemizygosity of the SLC6A4 in patient UWA106-3. Metaphase chromosome preparations from lymphoblasts of UWA106-3 were hybridised with 50G6 DNA. The two chromosomes 17 are arrowed: only one of them hybridised to the SLC6A4 probe; b Localisation by PCR of the centromeric breakpoint of the deletion in patient UWA106-3. DNA templates were as follows: (lane1) YAC 765D1; (lane2) genomic DNA from patient UWA106-3; (lane3) cell line UWA106-3-\#36 carrying the deleted chromosome 17; (lane4) cell line UWA106-3-\#41 carrying the non-deleted chromosome 17; (line5) the Chinese hamster RJK cell line. The primers (see Table1 and the Genome Database [http://gdbwww.gdb.org]) and sizes of PCR products are indicated. The specific PCR product of the E2F/2B primer pair is arrowed. 
genes should play a role in the understanding of neurofibromatosis as well as other developmental/psychiatric disorders.

\section{Acknowledgements}

We thank Eli Lilly and Company Ltd for financial support.

\section{References}

1 Lesch KP: Molecular biology, pharmacology and genetics of the serotonin transporter: psychobiological and clinical implications. In: Baumgarten HG, Göthert M eds. Serotoninergic Neurons and 5-HT Receptors in the CNS, vol 129, Handbook of Experimental Pharmacology. Springer-Verlag: Berlin and Heidelberg, 1997, pp 671-705.

2 Schedl A, Montoliu L, Kelsey G, Schutz G: A yeast artificial chromosome covering the tyrosinase gene confers copy numberdependent expression in transgenic mice. Nature 1993; 362: 258-261.

3 Bellis M, Pages M, Roizes G: A simple and rapid method for preparing yeast chromosomes for pulsed field gel electrophoresis. Nucleic Acids Res 1987; 15: 6749.
4 Kayes LM, Burke W, Riccardi VM et al: Deletions spanning the neurofibromatosis 1 gene: identification and phenotype of five patients. Am J Hum Genet 1994; 54: 424-436.

5 Edelhoff S, Ayer DE, Zervos AS et al: Mapping of two genes encoding members of a distinct subfamily of MAX interacting proteins: MAD to human chromosome2 and mouse chromosome6, and MXI1 to human chromosome 10 and mouse chromosome19. Oncogene 1994; 9: 665-668.

6 Ogilvie AD, Battersby S, Bubb VJ et al: A polymorphism of the serotonin transporter gene is associated with susceptibility to major affective disorder. Lancet 1996; 347: 731-733.

7 Heils A, Teufel A, Petri Set al: Allelic variation of human serotonin transporter gene expression. J Neurochem 1996; 66: 2621-2624.

$8 \mathrm{Li} \mathrm{Y}, \mathrm{O}^{\prime}$ Connell P, Breidenbach HH et al: Genomic organization of the neurofibromatosis 1 gene (NF1). Genomics 1995; 25: 9-18.

9 Gelernter J, Pakstis AJ, Kidd KK: Linkage mapping of serotonin transporter protein gene SLC6A4 on chromosome17. Hum Genet 1995; 95: 677-680.

10 Ramamoorthy S, Bauman AL, Moore KR et al: Antidepressant- and cocaine-sensitive human serotonin transporter: molecular cloning, expression, and chromosomal localization. Proc Natl Acad Sci USA 1993; 90: 2542-2546.

11 Riley DA, Tan F, Miletich DJ, Skidgel RA: Chromosomal localization of the genes for human carboxypeptidase D (CPD) and the active 50-kilodalton subunit of human carboxypeptidase $\mathrm{N}$ (CPN1). Genomics 1998; 50: 105-108. 